\title{
Setting up a regional network to screen newborns for congenital hypothyroidism in Southern province in Sri Lanka
}

\author{
Manjula Hettiarachchi \\ Senior Lecturer in Nuclear Medicine, Nuclear Medicine Unit, Faculty of Medicine, University of Ruhuna, Galle. \\ e-mail address of the corresponding author, Dr.M. Hettiarachchi:manjula.hettiarachchi@gmail.com
}

\begin{abstract}
In Sri Lanka, until recently there has been no programme to screen newborns for Congenital Hypothyroidism. The Nuclear Medicine Unit has completed a pilot study in 2006-2007 to assess the feasibility and identify challenges in establishing such programme. Then a regional network on Newborn Screening was established in early 2008 and 4 institutions (2 Base Hospitals and 1 each District and General Hospitals) have already participating in the network. Out of the 1581 newborns screened, one true positive child with Congenital Hypothyroidism was identified. The findings are highlighted to have a national programme on Newborn Screening.
\end{abstract}

\section{Introduction}

It has been estimated that 50,000 newborns each year are at risk for Congenital Hypothyroidism $(\mathrm{CH})$ in the South East Asian region ${ }^{1}$. Congenital Hypothyroidism is a common cause of preventable mental retardation. In developed countries, newborn babies are routinely screened for $\mathrm{CH}$, for over 40 years. However, the developing countries have begun to address this concern only in the past decade. In Sri Lanka, no such screenings have been conducted until August 2005, when the Nuclear Medicine Unit of the Faculty of Medicine, Peradeniya conducted screening of infants born in Gampola Teaching hospital and Base hospitals Mawanella and Nikaweratiya ${ }^{2}$. Due to incidence of high $\mathrm{CH}$ of the hospitals, need for implementing national screening programme for $\mathrm{CH}$ was proposed. International Atomic Energy Agency (IAEA) conducted a conference 'Neonatal Screening for Congenital Hypothyroidism (NSCH) in Sri Lanka' in January 2006. As a result of this conference, a pilot study was instituted in Teaching
Hospital Mahamodara (THM) to assess the feasibility of a regional screening programme for $\mathrm{CH}$ in Southern province in Sri Lanka.

\section{Phase I- a pilot study}

A pilot study to screen newborns for Congenital Hypothyroidism was embarked on $3^{\text {rd }}$ October 2006 with the approval from the Ethical Review Committee of the Faculty of Medicine, University of Ruhuna. Written consents of the mothers of newborns were obtained to participate in this $\mathrm{CH}$ screening project. Before mothers were discharged from the hospital, blood was drawn using blood spot technique for this project. Heel-prick blood spots were collected on a special filter paper (Schleicher and Schuell No 903). Air dried blood spots were stored in a sealed plastic box and transferred to the Nuclear Medicine laboratory. Samples with poor quality or inadequate spot were rejected. Accepted samples were given a reference number and processed for thyroid stimulating hormone (TSH) measurement using radioimmunoassay methodology using assay kits obtained from NETRIA Limited, United Kingdom. Neonates with blood spot TSH concentration of $20 \mathrm{mU} / \mathrm{L}$ or above in whole blood after 72 hours of birth were considered at risk for $\mathrm{CH}^{1}$ and were recalled for serum confirmation. The cut-off value for TSH in the blood spots collected prior to 72 hours of life was set at $40 \mathrm{mU} / \mathrm{L}^{1}$. A total of 1650 infants were screened by end of August 2007. Only few blood spots $(n=6)$ were rejected due to poor quality (sample rejection rate was $0.4 \%$ ). 1348 neonates $(81.7 \%)$ were screened within 72 hours of birth.

Mean blood spot TSH value was $11.47 \mathrm{mU} / \mathrm{L}$ (95\% CI 10.90-12.01). When the blood spot TSH cut off of $20 \mathrm{mU} / \mathrm{L}$ was used, 244 neonates $(14.8 \%$; $95 \% \mathrm{CI}$ $14.1 \%-15.3 \%$ ) were identified as at risk. Of them, 
216 neonates who had TSH $<40 \mathrm{mU} / \mathrm{L}$ were not called for serum confirmation. Other 28 neonates (either TSH $>20 \mathrm{mU} / \mathrm{L}$ and sample collected after 72 hours of birth or TSH $>40 \mathrm{mU} / \mathrm{L}$ and sample collected before 72 hours of birth) were called for serum confirmation. Only 1 true positive case of hypothyroidism was identified among them so that the incidence of true $\mathrm{CH}$ was 1:1650 in the study. These results were published in Ceylon Medical Journal recently.

\section{Challenges identified}

Although there are 3 Obstetric wards functioning at THM our study was confined to one ward (Professorial Obstetric Unit). This was due to the fact that the hospital administration felt that the number of Paediatric House Officers was not adequate to attend to the extra work on our research project. As such, we employed pre-intern medical officers working as temporary demonstrators in the Faculty for sample collection and this was limited to one session (from $0830 \mathrm{hrs}$ to $1100 \mathrm{hrs}$ ) of weekdays (excluding holidays) because of their other commitments in the Faculty. None of the staff members from Department of Health (i.e. medical officers or nursing officers) participated in sample collection.

The total number of live births reported during the study period in professorial Obstetric Unit and Teaching Hospital, Mahamodara was 4,476 and 13,601 , respectively. In our study we have assessed only $12.1 \%$ of live births in T.H. Mamamodara. For effective implementation of a regional screening programme, the sample collection must be handled by the staff in the hospital concerned.

\section{Phase II - Setting up a Regional Network}

During the pre-congress workshop titled 'Role of Screening Programmes for better child health' for Annual Academic Sessions of the Galle Medical Association in September, 2007, I made a presentation highlighting the results of the pilot study that has already described above. As a followup measure, setting up a regional centre for Newborn Screening was discussed at this workshop. After several rounds of discussions we formally established the Newborn screening programme at Base Hospital Balapitiya, and the first sample was collected on $8^{\text {th }}$ December 2007.

The Perinatal Society of Sri Lanka has come forward to arrange a stakeholders meeting for the development of a regional network. This arrangement was made with the IAEA expert mission of Prof. Dang-Hwan Lee, Department of Paediatrics, Soon Chun Hyang University Hospital, Seoul, Korea to strengthen regional screening network for neonatal hypothyroidism in June 2008. Stakeholders from all regional hospitals were represented at the discussion and their view on collection of specimens, transportation, analysis, reporting and counselling was discussed at length. The District Hospital: Akuressa, Base Hospital: Kamburupitiya and General Hospital: Matara joined the programme recently. The numbers of samples received and analyzed up to 20th May 2009 are presented in Table 1.

Table 1 - No of samples received for blood spot assay (up to $20^{\text {th }}$ May 2009)

\begin{tabular}{|l|l|l|}
\hline Hospital & Stating date & No of samples \\
\hline BH Balapitiya & $08-12-2007$ & 1411 \\
\hline BH Kamburupitiya & $01-03-2009$ & 81 \\
\hline GH Matara & $01-03-2009$ & 75 \\
\hline DH Akuressa & $10-03-2009$ & 14 \\
\hline
\end{tabular}

The samples were collected by the staff of the respective hospitals on to the filter paper strips provided by the NMU and a special request form was provided to fill the delivery date/time and sample collection date / time with other contact information. The collected samples and filled request forms were received by NMU weekly. The reagents for sample analysis were obtained from the same supplier through Medical Supplies Division of the Ministry of Health.

Of the 1581 samples received, 78 samples were rejected due to insufficient blood spots for analysis. Only 15 samples were collected after 72 hours of birth. All other samples were collected within first 48 hours of birth. Mean blood spot TSH value was $7.51 \mathrm{mU} / \mathrm{L}$ (SD 6.60) and only 3 samples showed blood spot TSH values above $40.0 \mathrm{mU} / \mathrm{L}$. These 3 neonates (2 from BH Balapitiya, 1 from $\mathrm{BH}$ Kamburupitiya) were recalled for serum TSH and free $\mathrm{T}_{4}$ assessment. Two of them had normal age appropriate serum hormone levels. 
The other child who had blood spot TSH level of $177.0 \mathrm{mU} / \mathrm{L}$, showed following clinical features: (on $29^{\text {th }}$ day of life - the day we obtained serum confirmation) - mild icterus, excessive sleepiness, constipation and coarse facial appearances suggestive of congenital hypothyroidism. His serum levels are as follows:

TSH level $\quad-29.96 \mathrm{mU} / \mathrm{L}$ (reference range $1.7-9.1 \mathrm{mU} / \mathrm{L}$ )

Free $\mathrm{T}_{4}$ level - $<5.0 \mathrm{pg} / \mathrm{L}$ (reference range 10.3- $25.8 \mathrm{pg} / \mathrm{L}$ )

So far only 1 true positive case of congenital hypothyroidism was identified since the establishment of the regional centre for Newborn Screening. It is our hope that paediatricians of the other health institutions in Southern Province would consider obtaining this service. An implementation of a national neonatal screening programme for $\mathrm{CH}$ is a long due need for the country and will bring about a considerable improvement in child healthcare.

\section{Acknowledgements}

I appreciate the efforts made by the Prof. Sujeewa Amarasena, Department of Paediatrics and then President, Perinatal Society of Sri Lanka to establish the regional network in Southern Province. The link between us and B.H. Balapitiya was strengthened since implementation of the programme. Dr. Manohari Madarasinghe, Consultant Paediatrician of the Base Hospital, Balapitiya immensely contributed to the collaborative work. Furthermore, consultant Paediatricians, all medical and nursing officers in B.H. Balapitiya \& Kamburupitiya, D.H. Akuressa and G.H. Matara and the staff of the Nuclear Medicine Unit, who are involved in this network implementation, are duly acknowledged. Efforts of Mr. P.H. Nadun Suranga and other technical officers of the Nuclear Medicine Unit for timely analysis of blood spot samples are greatly appreciated.

\section{References}

1. Therrell BL, Padilla CD. Screening of Newborns for congenital Hypothyroidism; Guidance for Developing Programs, IAEA. Geneva 2005.

2. Nanayakkara D, Wijekoon A, Jiffry N, et al. Screening for congenital hypothyroidism in Government Hospitals in Sri Lanka. Proceedings of the Peradeniya University Research Sessions 2007; 12: 133-4.

3. Hettiarachchi M, Liyanage C, Liyanarachchi N. Screening newborns for congenital hypothyroidism. Ceylon Medical Journal 2009; 54(1): 29-30. 